\title{
Morpho-functional studies of the blood-brain barrier in streptozotocin-induced diabetic rats
}

\author{
P. Bouchard, L. D. Ghitescu, M. Bendayan \\ Department of Pathology and Cell Biology, University of Montreal, Montreal, Quebec, Canada
}

\begin{abstract}
Aims/hypothesis. We undertook the characterization of the capillary bed of the rat frontal cortex and their permeability properties in short-term and long-term diabetic rats.

Methods. Diabetes was induced by strepozotocin injection. Rats were maintained hyperglycaemic without insulin treatment during 4 to 5 months (short-term) and 8 to 13 months (long-term). Rats from an additional short-term hyperglycaemic group received an injection of exogenous dinitrophenylated albumin $15 \mathrm{~min}$ before being killed. Tissues were processed for electron microscopy and quantitative immunocytochemistry. Endogenous and dinitrophenylated exogenous albumin were revealed with high resolution over the capillary wall using specific antibodies and the protein A-gold complex. Morphometrical analyses were carried out.

Results. Albumin is transported across endothelial cells by plasmalemmal vesicles or caveolae and larger
\end{abstract}

vacuolar structures. This transport increased in diabetic rats by an increment in the number of vesicles. Albumin distribution across the capillary basement membrane showed that the restrictive properties of the basement membrane present in normoglycaemic rats are altered in the diabetic condition, as was its thickness. Similar alterations of the basement membrane structure and function were encountered in old normoglycaemic rats but to a lesser extent.

Conclusion/interpretation. The results indicate that diabetes seems to accelerate the ageing process of the vascular wall and that the central nervous system capillary bed is also a target for diabetic microangiopathy. [Diabetologia (2002) 45:1017-1025]

Keywords Blood-brain barrier, endothelium, basement membrane, vascular permeability, albumin, immunocytochemistry, diabetes.
The blood-brain barrier is a concept based on the fact that circulating substances reach equilibrium with the brain tissue at different rates, some of them at very low ones $[1,2,3]$. Structurally, three candidates could

Received: 28 December 2001 / Revised: 25 March 2002 Published online: 6 June 2002

C) Springer-Verlag 2002

Corresponding author: Dr. M. Bendayan, Département de Pathologie et Biologie Cellulaire, Faculté de Médecine, Université de Montréal, C.P. 6128 Succ. Centre Ville, Montreal, Québec, Canada. H3C 3J7, E-mail: Moise.Bendayan@Umontreal.ca Abbreviations: DNP-BSA, Dinitrophenylated bovine serum albumin; CNS, central nervous system; STZ, streptozotocin; PBS, 0.01 M phosphate buffer saline. be considered as key elements of this barrier, the capillary endothelial cells, their basement membrane and the astrocytes whose feet processes anchor the same basement membrane $[1,4,5,6]$. Some studies indicate however that the site of the blood-brain barrier lies mainly on the endothelial cell $[3,4]$. Morphological studies using electron dense tracers injected intravenously have shown that these do not cross the endothelium of the central nervous system blood vessels, or if they do, the penetration occurs at a very slow pace $[3,5,6,7]$. Brain capillaries are known to be of the continuous type with highly developed tight junctions and a paucity of plasmalemmal vesicles or caveolae [8]. In addition to the structural barrier, the passage of circulating substances can be restricted 
Table 1. Characteristics of control and diabetic rats

\begin{tabular}{lllclc}
\hline & & $\begin{array}{l}\text { Body weights } \\
(\mathrm{g})\end{array}$ & $\begin{array}{l}\text { Blood glucose } \\
\text { concentration } \\
(\mathrm{mmol} / \mathrm{l})\end{array}$ & $\begin{array}{l}\text { Insulin } \\
\text { concentrations } \\
(\mu \mathrm{U} / \mathrm{ml})\end{array}$ & $\begin{array}{l}\text { Brain capillary } \\
\text { basement membrane } \\
\text { thickness }(\mathrm{nm})\end{array}$ \\
\hline Short-term & Controls & $400.0 \pm 7$ & $7.0 \pm 0.5$ & $70.0 \pm 10.0$ & $132.1 \pm 2.1$ \\
& Diabetics & $290 \pm 30^{\mathrm{a}}$ & $32.8 \pm 0.5^{\mathrm{a}}$ & $29.8 \pm 3.5^{\mathrm{a}}$ & $157.2 \pm 2.3^{\mathrm{a}}$ \\
Long-term & Controls & $700 \pm 30^{\mathrm{b}}$ & $6.0 \pm 0.9$ & $51.0 \pm 3.5^{\mathrm{a}}$ & $143.1 \pm 2.2^{\mathrm{b}}$ \\
& Diabetics & $180 \pm 20^{\mathrm{a}}$ & $32.1 \pm 1.0^{\mathrm{a}}$ & $21.4 \pm 0.5^{\mathrm{a}}$ & $166.2 \pm 2.2^{\mathrm{a}}$ \\
\hline
\end{tabular}

a $p<0.05$ compared to corresponding controls

${ }^{\mathrm{b}} p<0.05$ compared to short-term control animals Mean values \pm SEM

further by a number of mechanisms including passive efflux, metabolic degradation and active cellular efflux mechanisms dependant on membrane-bound proteins such as the P-glycoprotein and the multidrug resistance proteins [9].

In diabetes, capillary endothelial cells and their basement membranes undergo major changes, particularly in the heart [10], retina [11, 12], and kidney $[13,14,15,16,17,18]$. For the nervous tissue, the perineural $[19,20,21]$ and endoneural capillaries [22, 23] were reported as getting altered too during diabetes. Due to their impact on the pathology of diabetes, several studies have focused on the changes occurring at the level of the renal glomerular wall showing alteration in renal filtration properties with extravasation of serum proteins [13, 14, 15, 24]. Mechanisms responsible for the glomerular permselectivity, such as size restriction, charge repulsion and molecular configurations of the basement membrane components have been found to undergo major changes $[18,25$, 26, 27, 28]. Similar alterations could take place at the blood-brain barrier, since loss of its integrity has already been documented during diabetes $[29,30,31$, 32] with changes in CNS blood capillary density $[29,33]$ and capillary basement membrane thickening $[34,35,36,37]$.

Post-embedding immunocytochemistry using colloidal gold as a marker [38] allows for the high-resolution localisation of a large variety of tissue and cell antigens. This approach has been applied successfully to show circulating proteins within vascular beds at steady state conditions or during perfusion experiments allowing for the delineation of transendothelial transport pathways across the vascular walls in control as well as in experimental and pathological conditions $[14,38,39,40,41,42,43,44]$. We thus investigated the distribution of endogenous albumin over the blood capillary wall of the CNS, as well as the dynamics of the exogenous albumin passage across the same capillary bed, both under control and diabetic conditions. Experiments were carried out on frontal cortex brain tissue from normoglycaemic and short- and long-term hyperglycaemic rats.
Control rats $(n=3)$ for each group

Diabetic rats $(n=5)$ for both the short-term and long-term groups

\section{Materials and methods}

A chronic hyperglycaemic state was induced in Sprague-Dawley male rats (100 g, Charles River, St-Laurent, Quebec, Canada) by a single intraperitoneal injection of streptozotocin (STZ, $70 \mathrm{mg} / \mathrm{kg}$ of body weight, in citrate buffer $0.1 \mathrm{~mol} / \mathrm{l}, \mathrm{pH} 4.5$ ) (Sigma-Aldrich Canada, Oakville, Ontario, Canada). Agematched control rats received an injection of the citrate buffer and remained normoglycaemic. The glycaemic state of the rats was assessed all through the experiment using Uriscan (VWRCanlab, Montreal, Canada) and Dextrostix (Miles, Ames, Ontario, Canada) reagent strips. The hyperglycaemic state developed in STZ-injected rats within the first $48 \mathrm{~h}$, and remained high during the entire length of the experiment. One group of STZ-injected rats $(n=10)$ was kept hyperglycaemic for 4 to 5 months and a second one $(n=5)$ for 8 to 13 months. Animals had free access to water and food, and did not receive insulin treatment. The hyperglycaemic rats showed lower weight gain, strong hyperglycaemia and low insulin concentrations when compared to the age-matched control normoglycaemic rats (Table 1). Experimental procedures were approved by the Committee of Deontology for experimentation on animals of the Université de Montréal.

At indicated time points, the rats were anaesthetised by an intraperitoneal injection of urethane and small tissue fragments (about $1 \mathrm{~mm}^{3}$ ) from the frontal cortex were sampled and immediately fixed by immersion with either $1 \%$ glutaraldehyde or $4 \%$ paraformaldehyde-lysine-periodate solution for $3 \mathrm{~h}$ at $4^{\circ} \mathrm{C}$. They were rinsed with $0.1 \mathrm{~mol} / \mathrm{l}$ phosphate buffer, dehydrated in graded methanol and embedded in Lowicryl K4M (Canemco, St-Laurent, Quebec, Canada) at $-20^{\circ} \mathrm{C}$ [38]. Ultrathin sections were cut and mounted on Parlodion-coated and carbon-coated nickel grids and processed for immunocytochemistry.

Five of the 4-5 months hyperglycaemic rats, and their corresponding controls, received an intravenous injection of $2 \mathrm{ml}$ of dinitrophenylated bovine serum albumin (DNP-BSA) (200 $\mathrm{mg}$, during 1 to $2 \mathrm{~min}$ ) in the jugular vein [40, 41]. Prior to this, $2 \mathrm{ml}$ of blood was retrieved with a heparinised syringe. After 15 min of DNP-BSA in circulation, the rats were killed by cervical dislocation. The frontal cortex was exposed and small samples of tissue were immediately fixed with $1 \%$-glu-

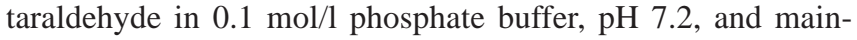
tained in the same fixative for $2 \mathrm{~h}$ at room temperature. Tissues were post-fixed with $1 \%$-osmium tetroxide, dehydrated in graded ethanol and finally embedded in Epon 812. Ultrathin sections were cut, mounted on Parlodion-carbon-coated nickel grids, and processed for the immunocytochemical labelling of DNP-BSA. The dinitrophenylated borine serum albumin was prepared according to methods described previously [40]. 
To detect endogenous rat albumin and BSA-DNP, the postembedding protein A-gold immunocytochemical technique was applied [38], using specific polyclonal anti-rat albumin (Cappel, Organon Technika, Westchester, Pensylvania, USA), and anti-DNP (Dimension Laboratories, Mississauga, Ontario, Canada) antibodies. For endogenous rat albumin, tissue sections were first incubated for $30 \mathrm{~min}$ at room temperature on a drop of $0.15 \mathrm{~mol} / \mathrm{l}$ glycine, followed by $1 \%$-fish gelatin, and finally on a drop of the specific anti-rat albumin antibody at the final dilution of $1 / 100$ in PBS, overnight at $4^{\circ} \mathrm{C}$. Next, the grids were rinsed with PBS and quenched by an incubation with $1 \%$ gelatin for $15 \mathrm{~min}$. Antigen-antibody complexes were shown by an incubation with the protein A-gold complex (10 $\mathrm{nm}$ gold particles) at room temperature for $30 \mathrm{~min}$. Sections were then washed with PBS and distilled water, stained with 3\%-uranyl acetate and examined with a Philips EM-410 electron microscope. The protein A-gold complex was prepared according to published results [38].

To show DNP-BSA, thin sections of the glutaraldehydeosmium fixed and Epon-embedded tissues were first incubated on a drop of a saturated solution of sodium metaperiodate at room temperature for $30 \mathrm{~min}$ and washed with distilled water. The grids were then incubated on drops of $0.15 \mathrm{mmol} / \mathrm{l}$ glycine and $1 \%$-fish gelatin for $15 \mathrm{~min}$ at room temperature each, and transferred to a drop of the specific anti-DNP antibody at the final dilution of $1 / 300$, for $2 \mathrm{~h}$ at room temperature. Sections were washed with PBS and transferred to a drop of the protein A-gold complex for $30 \mathrm{~min}$ at room temperature. The tissue sections were washed in PBS, rinsed in water and dried. Finally, staining with uranyl acetate and lead citrate was carried out prior to examination with the electron microscope.

The specificity of the labellings was assessed by control experiments: incubations with protein A-gold complex alone omitting the antibody step, and incubations with a solution of each antibody to which the specific antigen, either rat albumin or DNP, was added in excess, followed by the protein A-gold complex.

Densities of the different cytochemical labellings were determined by morphometry. Labellings for albumin were evaluated over the capillary lumen, the endothelial cells and the basement membrane using the Videoplan 2 image processing system (Carl Zeiss Inc., Toronto, Ontario, Canada). Images were recorded at $\times 16900$ and printed at the final magnification of $\times 42250$. Areas occupied by the lumen, endothelial cells and basement membrane were measured by direct planimetry, and the number of gold particles within those areas was counted. Fifty different fields originating from of at least ten capillary profiles were recorded from at least five tissue sections for each animal. Labelling densities over the endothelial cells and basement membranes were expressed as a percentage of that recorded over the vascular lumen to allow for normalisation of the data and for comparative evaluations.

The distribution of endogenous and exogenous albumin over the thickness of the capillary basement membrane was evaluated $[14,38]$ using the same image processing system. Recording of the images was carried out at $\times 31000$ and enlarged to the final magnification of $\times 154330$. The distance between each gold particle and the abluminal plasma membrane of the endothelial cell was measured. At the same site, the thickness of the basement membrane from the endothelial abluminal plasma membrane to the astrocytic or pericytic plasma membrane, was also measured. The ratio, $\mathrm{R}$ between these two values was calculated. $R$ values vary from 0 to 1,0 being for gold particles located at the abluminal plasmalemmal membrane and 1 for those touching the membrane of the astrocytes or pericytes. The data (150250 per animal) were generated from 10 to 12 capillary profiles from each animal of each group.
The density and the distribution of plasmalemmal vesicles or caveolae at the two poles (luminal and abluminal) of the endothelial cells were measured in tissues of normal and shortterm diabetic rats. About 90 fields of endothelial cell cytoplasm were recorded from at least 10 capillary profiles per rat, from five tissue sections at the final magnification of $\times 42250$. The length of the endothelial cell was measured, while the width of the endothelium was arbitrarily separated halfway into luminal and abluminal regions. The total number of plasmalemmal vesicles in each region was counted and reported to the length of the endothelial cell. The density of plasmalemmal vesicles, in luminal and abluminal regions of the endothelial cell was calculated as $\mathrm{D}_{\text {lum }}=$ (number of luminal plasmalemmal vesicles/length of endothelium) and $\mathrm{D}_{\text {ablum }}=$ (number of abluminal plasmalemmal vesicles/length of endothelium). A total of about 5000 vesicles was included in the evaluation. In a second study, the density of plasmalemmal vesicles per endothelial cytoplasmic area was also evaluated using the same documents already recorded. Density was calculated as the number of plasmalemmal vesicles per square micrometer of endothelial cytoplasm. The endothelial cytoplasmic areas evaluated excluded nuclei, peri-nuclear cytoplasmic and peri-junctional regions. Finally, upon labelling DNP-BSA, the percentage of labelled vesicles was calculated.

All the parameters were estimated in both control and diabetic conditions. Comparative evaluations between groups were established through statistical analysis using the MannWhitney $\mathrm{U}$ test with a significance threshold of a $p$ value of less than 0.05 .

\section{Results}

The morphological features of the capillary endothelial cells in the CNS seem to be similar in control and diabetic rats (Fig. 1). In both conditions, the endothelium is of the continuous type surrounded by a welldefined basement membrane between endothelial and astrocytic or pericytic cells. The thickness of this basement membrane increased in the diabetic condition as established by the morphometrical evaluation (Table 1 ), the increase being more important for the long-term diabetic rats. Endothelial cells are joined by tight junctional complexes, which remain intact in the hyperglycaemic condition. The endothelial cells are thin and organelles are mainly in the vicinity of the nuclei (Fig. 1). These include RER, mitochondria and prominent Golgi apparatus with cisternae parallel to the plasma membranes. Plasmalemmal vesicles or caveolae, either open at the luminal or abluminal plasma membranes or close in the cytoplasm, show a particular distribution. They seem to be in higher numbers in the abluminal region of the endothelial cells (Fig. 1), a fact which was confirmed by the morphometrical evaluation (Table 2 ). This was true for tissues from control as well as from STZ-injected rats. On the other hand, whereas the number of plasmalemmal vesicles (Table 2 ) is among the lowest compared with other capillary beds, their density increased in diabetes, with numbers almost double to those found in tissues of control rats (Table 2 ). 
Table 2. Number and topographical location of caveolae or plasmalemmal vesicles in the brain cortex capillary endothelium

\begin{tabular}{llll}
\hline & $\begin{array}{l}\text { Number of vesicles per } \\
\text { length of luminal front } \\
(\mathrm{ves} / \mu \mathrm{m})\end{array}$ & $\begin{array}{l}\text { Number of vesicles per } \\
\text { length of abluminal front } \\
(\mathrm{ves} . / \mu \mathrm{m})\end{array}$ & $\begin{array}{l}\text { Number of vesicles per } \\
\text { area of endothelium } \\
\left(\mathrm{ves} . / \mu \mathrm{m}^{2}\right)\end{array}$ \\
\hline Control & $1.86 \pm 0.21$ & $2.94 \pm 0.36$ & $16.67 \pm 0.49$ \\
Diabetic & $4.01 \pm 0.26^{\mathrm{a}}$ & $5.12 \pm 0.30^{\mathrm{a}}$ & $28.19 \pm 1.97 \mathrm{a}$ \\
\hline
\end{tabular}

5000 vesicles were considered for each group

${ }^{a} p<0.05$. When compared to corresponding controls

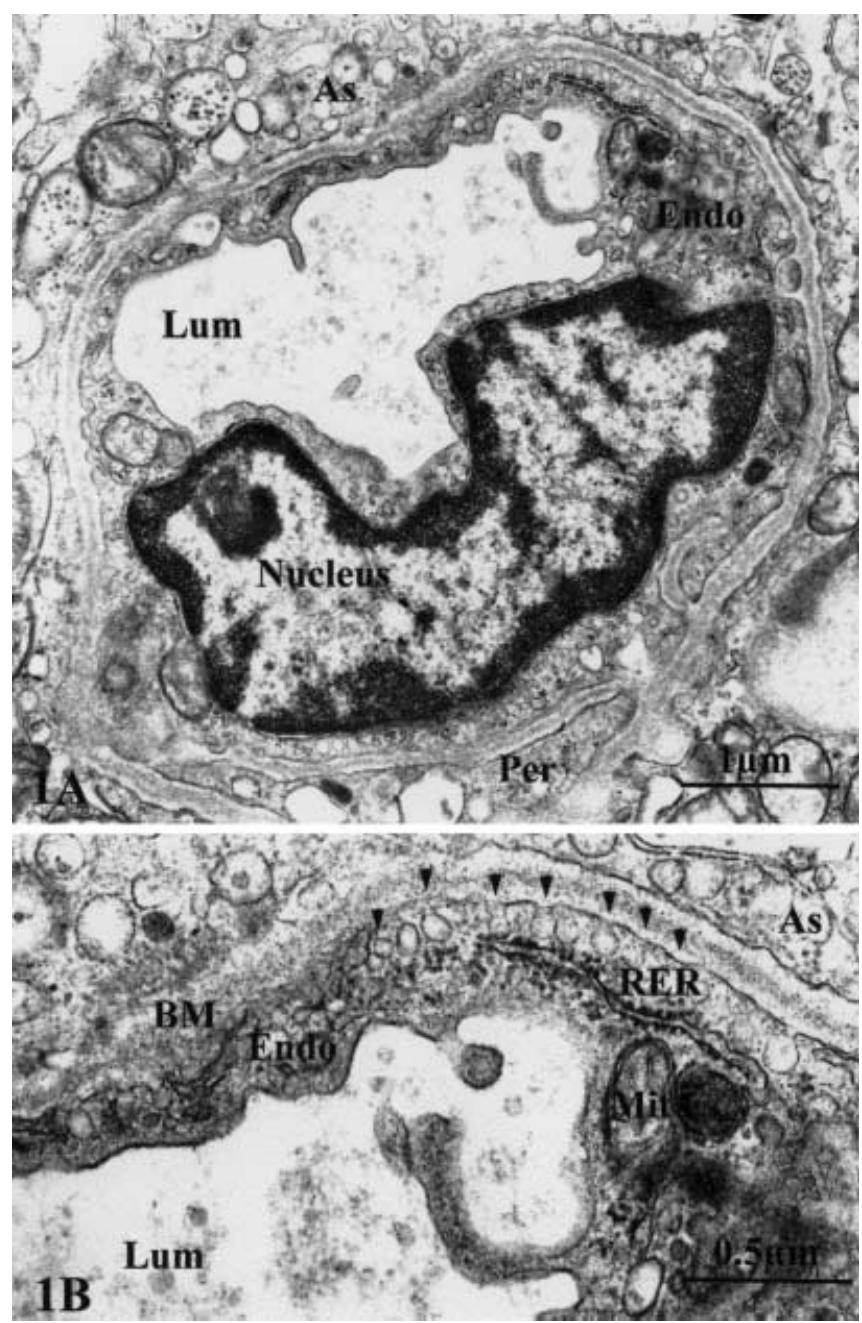

Fig. 1A, B. Rat brain capillary (frontal cortex). Normoglycaemic rat. The capillary is composed by an endothelial cell (Endo) surrounding the capillary lumen (Lum). Around the capillary, pericytes (Per) and astrocytes (As) are present (A). Within the cytoplasm of the endothelial cell, usual organelles are found: nucleus, rough endoplasmic reticulum (RER), mitochondria (Mit), Golgi apparatus and plasmalemmal vesicles (some are indicated by arrowheads) (B). The basement membrane (BM) separates the endothelial cell from the astrocytes or the pericyte

To establish the steady state distribution of circulating albumin as well as the pathway for its transendothelial transport, quantitative immunocytochemistry was carried out. Immunogold labelling for endogenous albumin was found over the capillary lumen, the
Mean values \pm SEM

Control rats $(n=3)$; diabetic rats $(n=5)$ short-term experiment
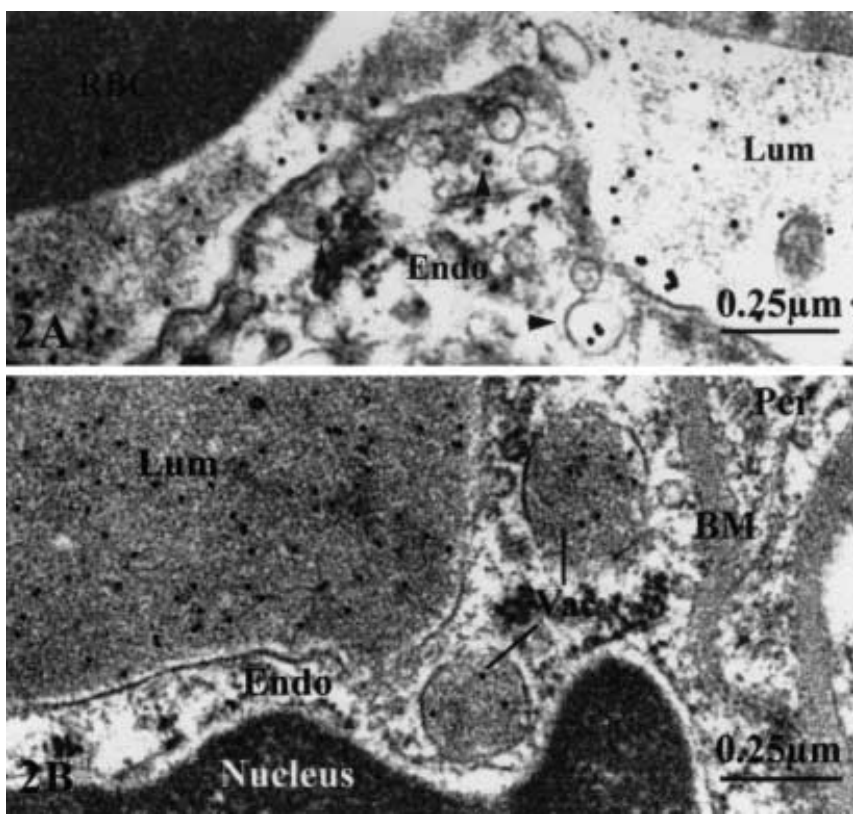

Fig. 2A, B. Ultrastructural localisation of albumin. Normoglycaemic rat. Within the endothelial cell (Endo), plasmalemmal vesicles (arrowheads) appear labelled for either endogenous rat albumin (2A) or for DNP-BSA (2B); the labelling is also present within the lumen (Lum) where we can recognise a red blood cell (RBC). Large vacuolar structures (Vac) and plasmalemmal vesicles, both labelled for albumin are present in endothelial cells. Basement membrane (BM) and pericyte (Per)

endothelial cells and their basement membrane. Over the cells, the gold particles were preferentially associated with the plasmalemmal vesicles either open at the luminal or abluminal fronts or closed in the cytoplasm (Fig. 2A). In addition to vesicles, larger vacuolar profiles were also present in the endothelial cytoplasm. These were few in number. The content of the vacuolar profiles was similar to that found in the lumen; this content was labelled by numerous gold particles (Fig. 2B). The non-specific labelling found over the cytosol and organelles such as mitochondria and nuclei was very low. Also, very few gold particles were detected within the intercellular clefts. In the pericapillary space, a considerable number of gold particles was present over the basement membrane (Fig. 3). A similar pattern of labelling was found in tissues of control and diabetic animals. However, quantitative evaluations of the densities of labelling showed in- 
Table 3. Evaluation of the labelling for endogenous albumin in the capillary wall of the brain cortex

\begin{tabular}{|c|c|c|c|c|}
\hline & \multicolumn{2}{|l|}{ Short-term } & \multicolumn{2}{|l|}{ Long-term } \\
\hline & Control (\%) & Diabetic (\%) & Control (\%) & Diabetic (\%) \\
\hline Basement membrane & $6.56 \pm 1.44$ & $17.49 \pm 1.72^{\mathrm{a}}$ & $13.82 \pm 1.14^{\mathrm{b}}$ & $25.66 \pm 1.88^{a}$ \\
\hline
\end{tabular}

Expressed as percentage of the labelling in the vascular lumen ${ }^{a} p<0.05$ when compared to corresponding controls

$\mathrm{b} p<0.05$. When compared to short-term controls

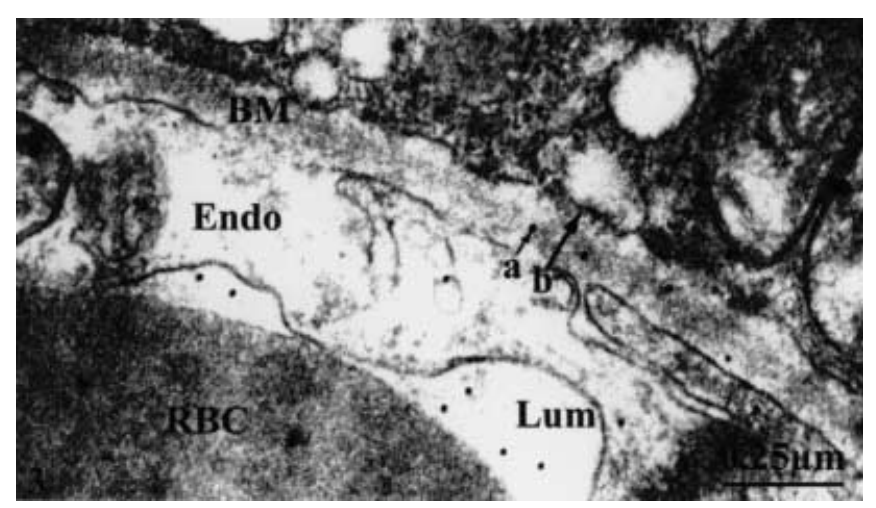

Fig. 3. Evaluation of the albumin distribution across the capillary basement membrane. Hyperglycaemic rat, short-term experiment. Gold particles showing DNP-BSA are present over the basement membrane (BM). The ratio value $(R)$ is calculated according to the formula: $\mathrm{R}=$ [distance gold particle-endothelial plasma membrane (a)]/[basement membrane thickness (b)]

creases for endogenous albumin at the level of the endothelial cells and their basement membranes in diabetic condition when compared with age-matched control rats (Table 3). The comparative evaluations carried out on tissues from the short- and the longterm normoglycaemic and hyperglycaemic animals also indicated increases in labelling along with the age of the rats (Table 3). These results reflect the steady state distribution of endogenous albumin across the brain capillary wall. To have an image on the dynamics of albumin transport in the capillary bed, an exogenous tracer, DNP-BSA, was injected and maintained in circulation for $15 \mathrm{~min}$. The immunogold labelling for DNP-BSA over the CNS capillary wall showed similar patterns of distribution as endogenous albumin, over capillary lumina, endothelial cells and basement membrane. Over the endothelial cells, the labelling, although of relatively low intensity, was mainly associated with plasmalemmal vesicles and larger endothelial vacuoles (Figs. 2A, B). Tissues from the diabetic animals showed an increase in the labelling of the endothelial cells. Morphometrical evaluations confirmed again that albumin, this time exogenous, is taken up by the brain capillary endothelial cells via its transcytotic system and in higher amounts in diabetic rats (Table 4).
Mean values \pm SEM

Control rats $(n=3)$ in each group; diabetic rats $(n=5)$ in each group

Table 4. Evaluation of the density of labelling for DNP-BSA over the endothelium and the basement in brain capillaries

\begin{tabular}{lll}
\hline & Control (\%) & Diabetic (\%) \\
\hline Endothelial profile & $4.42 \pm 0.46$ & $10.16 \pm 1.78^{\mathrm{a}}$ \\
Basement membrane & $7.52 \pm 1.09$ & $13.45 \pm 1.81^{\mathrm{a}}$ \\
\hline
\end{tabular}

Expressed as percentage of labelling in the vascular lumen ${ }^{\mathrm{a}} p<0.05$. When compared to corresponding controls Mean values \pm SEM

Control rats $(n=3)$; diabetic rats $(n=5)$ short-term experiment

Table 5. Evaluation of the number of caveolae or plasmalemmal vesicles labelled for DNP-BSA

\begin{tabular}{lll}
\hline & Control (\%) & Diabetic (\%) \\
\hline Labelled vesicles & $7.72 \pm 1.37$ & $8.21 \pm 0.66$ \\
\hline
\end{tabular}

4000 vesicles were considered in each group

Mean values \pm SEM

Control rats $(n=3)$; diabetic rats $(n=5)$ short-term experiment

Since plasmalemmal vesicles or caveolae were preferentially labelled for endogenous as well as exogenous albumin, we decided to evaluate the percentage of labelled vesicles. Whether in control or diabetic conditions, the percentage of the vesicles showing a labelling was similar, in the range of $8 \%$ despite the fact that there are twice as many vesicles in cells of hyperglycaemic rats (Table 5 ).

The distribution of the labelling over the basement membrane thickness is indicative for the degree of diffusion of albumin across the basement membrane (Fig. 3). Differences were found between young and old normoglycaemic rats (Fig. 4) as well as in the diabetic condition (Fig. 5). In older animals, the distribution of albumin has higher R-values which correspond to a displacement of albumin towards the astrocytic side of the basement membrane. This indicates that the basement membrane of older rats even in normoglycaemic condition, is less restrictive to the passage of albumin. In short-term diabetic rats a slight increase in the R-value was registered compared to the control rats (Fig. 5A). The distribution shifted towards the astrocytic or pericytic side of the basement mem- 


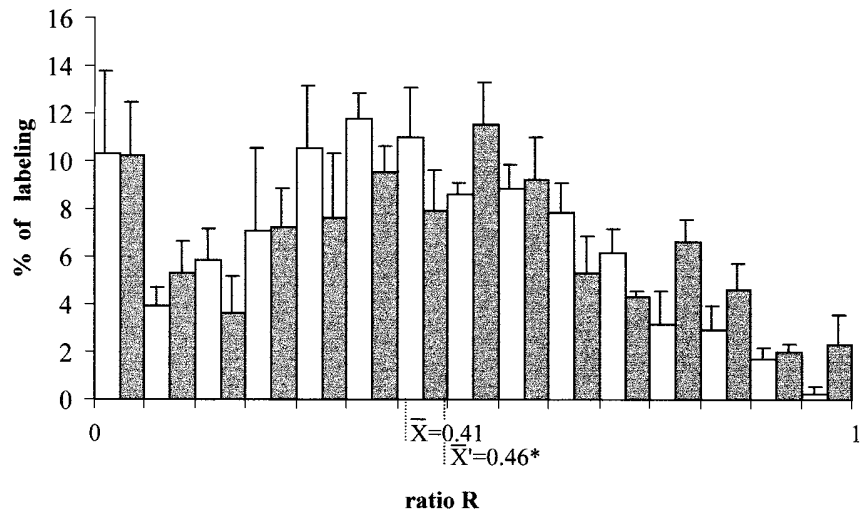

Fig. 4. Distribution of endogenous rat albumin across the basement membrane in normoglycaemic rats. Distribution of rat albumin immunolabelling in the central nervous system capillary basement membrane in young (4 months) (white columns) and old (12 months) (black columns) normoglycaemic rats as expressed in ratio values (R). The histograms are similar, except for a more uniform distribution of albumin and a mean value (X') higher for the older animals ( $\left.{ }^{\mathrm{a}} p<0.05\right)$
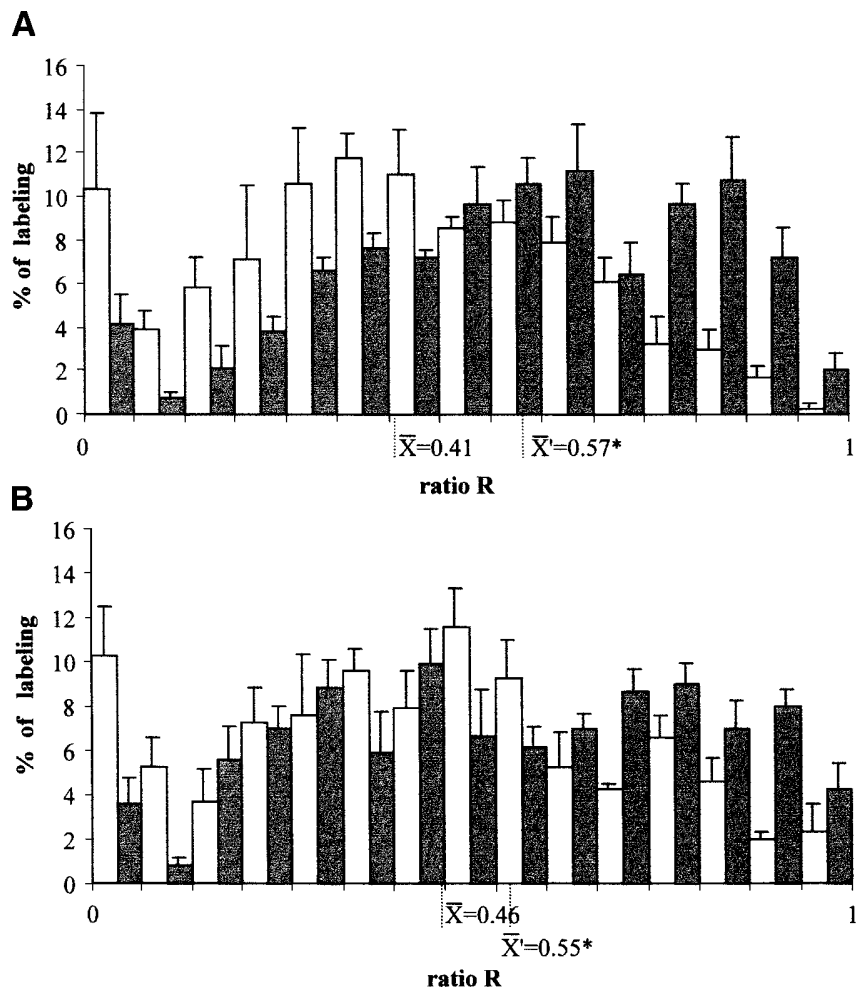

Fig. 5A, B. Distribution of endogenous rat albumin across the basement membrane. Distribution of albumin immunolabelling in the capillary basement membrane in short-term (4 months) (A) and long-term (8-13 months) (B) normoglycaemic (white columns) and hyperglycaemic (black columns). The histogram of short-term animals (A) is similar to that of long-term animals (B), distributions however shifted towards the astrocytic or pericytic side of the basement membrane for the hyperglycaemic animals compared to a more endothelial distribution for the normoglycaemic animals. Significant differences in $\mathrm{R}$ values exists between normoglycaemic and hyperglycaemic conditions in both short-term and longterm rats $\left({ }^{\mathrm{a}} p<0.05\right)$

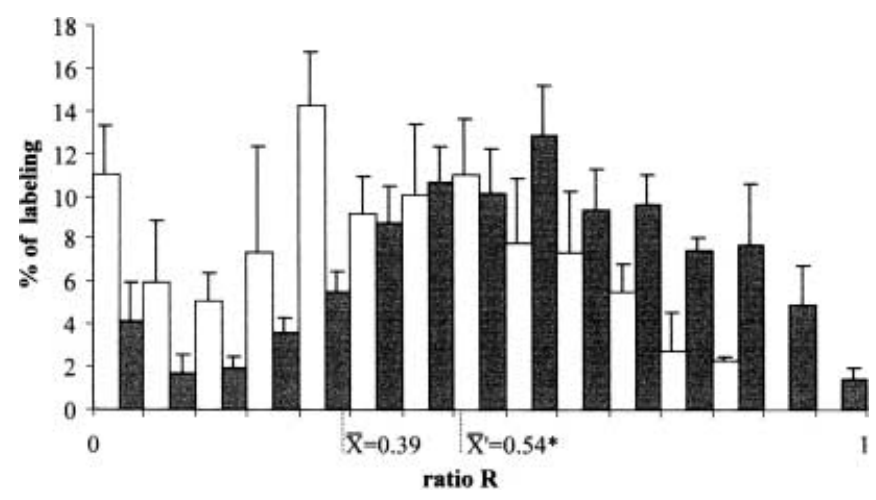

Fig. 6. Distribution of DNP-BSA across the basement membrane. Distribution of DNP-BSA immunolabelling in the capillary basement membranes in normoglycaemic (white columns) and hyperglycaemic (black columns) rats. The histogram of normoglycaemic rats shows a rather subendothelial distribution of DNP-BSA whereas for the hyperglycaemic rats the distribution seems more uniform. Significant differences in $\mathrm{R}$ values exist between normoglycaemic and hyperglycaemic animals $\left({ }^{\mathrm{a}} p<0.05\right)$

brane. A similar result was also recorded for the longterm diabetic rats (Fig. 5B). Concerning the distribution of exogenous albumin across the basement membrane, similar increases in $\mathrm{R}$ values were obtained for the hyperglycaemic rats (Fig. 6), supporting the fact that the restrictive characteristics of the brain capillary basement membrane are altered during diabetes.

\section{Discussion}

Protein A-gold immunocytochemical technique has been used to show circulating serum albumin in the CNS blood capillary bed. The passage of this protein across the capillary wall was comparatively evaluated on brain frontal lobe tissues from age-matched normoglycaemic and STZ-injected rats at two intervals after the onset of the hyperglycaemic state. The relation between the density of the immunolabelling and the actual concentration of the detected tracer has been well established [41, 42]. Changes in albumin permeability were found in normoglycaemic rats along with their age as well as between normo-glycaemic and hyperglycaemic rats. These changes go along with previous biochemical data on the cerebrospinal fluid protein content which showed increases in diabetic patients [45, 46, 47, 48]. However, unlike the lymph, the amount of plasma proteins present in the cerebrospinal fluid, is only an approximate index of the permeability of the blood-brain-barrier. The cerebrospinal fluid is not brain interstitial fluid, but rather the result of an active process of secretion by the epithelial cells of the choroids plexus. The CNS capillary endothelial cells of the hyperglycaemic rats show higher amounts of albumin immunolabelling associated to plasmalemmal vesicles. These increases were consistent for the 
endogenous as well as the exogenous albumin. Increases were also found in the total number of plasmalemmal vesicles. Together these results indicate that transport of albumin via vesicular structures undergoes changes during the hyperglycaemic condition. These changes are mainly caused by the increase in the total number of vesicular profiles in endothelial cells of the CNS capillary bed and not by an increase in the vesicle loading since the percentage of labelled vesicles did not change in hyperglycaemic conditions. Similar increases in the total number of plasmalemmal vesicles was reported in endothelial cells of STZinjected animals at the level of the muscle capillaries [49]. Also a similar increase in albumin transport by endothelial cells was reported in mesenteric capillaries of hyperglycaemic animals [41]. The low number of the plasmalemmal vesicles in the CNS endothelial cells has been well established and is considered as one of the features responsible for the low permeability to macromolecules attributed to the blood-brain barrier $[1,5,6,8,43]$. The increase in their number could then contribute to an alteration in permeability found for the blood-brain barrier during diabetes [29, 50, 51, 52]. Another interesting result concerns the asymmetry between the luminal and the abluminal distributions of plasmalemmal vesicles in endothelial cells. Such asymmetry was already reported in the brain [53] as well as in other tissues [53, 54, 55, 56] and raises concern with regards to the vesicular transcytotic models of endothelial transport. Cellular mechanisms regulating capillary wall permeability remain an ongoing debate and several paths such as the shuttling of vesicles, the existence of patent transendothelial channels and the inter-endothelial clefts have been proposed for the passage of molecules [42, $56,57,58]$. Other endothelial structures, such as the vesicular-vacuolar organelles [59] and vesiculo-tubular systems $[56,57]$ were reported to be involved in the transendothelial transport of serum proteins. In our study, large vacuolar profiles were found in endothelial cytoplasm showing intense labelling for albumin. Some of these vacuoles were open either at the luminal or abluminal fronts, while others seemed to be closed within the endothelial cytoplasm. Similar vacuolar structures were reported in aortic endothelium [60], in capillaries from various tumours [59, 61], from the CNS $[62,63]$, and from the cardiac muscle [52]. It has been shown that these vacuoles represent distinct endothelial cell structures that participate in the transendothelial transport of macromolecules [60, 61, 63].

In what concerns the distribution of albumin in the basement membrane, this seemed to undergo changes along with the age of the animals and in the diabetic condition. Labelling for circulating albumin was present in capillary basement membranes in all groups of rats. In tissues from normoglycaemic rats, the labelling was more concentrated on the endothelial side of the basement membrane than on the astrocytic or pericytic side, suggesting that similar to the glomerular wall [14], the basement membrane of brain capillaries must contribute to the restricted passage of proteins across the capillary wall $[29,51,52]$. In contrast, the basement membrane of hyperglycaemic rats showed an increase in albumin amounts and changes in albumin distribution. Albumin was no longer retained on the endothelial side of the basement membrane, but rather spread to the astrocytic or pericytic side. These changes became more important along with the duration of the hyperglycaemic state. For the glomerular permselectivity, the molecular conformation of the basement membrane matrix and the concentrations of glycation of circulating proteins are assumed to be responsible for the restricted passage of serum proteins [64]. Changes in these characteristics lead to alterations in permeability properties [64]. Diabetes or prolonged periods of hyperglycaemia do affect drastically the glycation of proteins, glomerular basement membrane integrity and its filtration properties [15, 18, 25, 27, 28]. Previous [51] and present results indicate that this may also be the case for the blood-brain barrier. Since changes in albumin distribution across the basement membrane was also detected in normoglycaemic rats in relation to their age suggests that diabetes could accelerate a normal ageing process taking place at the blood-brain barrier.

Acknowledgements. The authors acknowledge D. Gingras, I. Londoño, G. Mayer for their appreciated assistance and J. Léveillé for photographic work. This study was supported by grants from the Association Diabete Quebec, the Juvenile Diabetes Foundation and the Canadian Institutes of Health Research. This article represents part of the work required for the fulfilment of the M.Sc. program of P. Bouchard.

\section{References}

1. Peters A, Palay SL, Webster HF (1991) The fine structure of the nervous system, 3rd edn. Oxford University Press, New York

2. Renkin EM, Curry FE (1978) Transport of water and solute across capillary endothelium. In: Giebish G, Tosteson DC, Ussing UU (eds) Transport organs. Membrane transport in biology. Springer, Berlin, pp 1-45

3. Reese TS, Karnowsky MJ (1967) Fine structural localization of a blood-brain barrier to exogenous peroxidase. J Cell Biol 34:207-217

4. Poirier J, Fleury J, Ghérardi R (1983) La barrière hématoencéphalique. Données morphologiques. Rev Med Interne 4:131-144

5. Bradbury MW (1984) The structure and function of the blood-brain barrier. Fed Proc 43:186-190

6. Brightman MW (1977) Morphology of blood-brain interfaces. Exp Eye Res [Suppl 25]:1-25

7. Comber BL, Stewart PA (1985) Morphometric analysis of CNS microvascular endothelium. Microvasc Res 39:99-115

8. Stewart PA (2000) Endothelial vesicles in the blood-brain barrier: are they related to permeability? Cell Mol Neurobiol 20:149-163 
9. Ling V (1997) Multidrug resistance: molecular mechanisms and clinical relevance. Cancer Chemother Pharmacol 40:S3-S8

10. Yamaji T, Fukuhara T, Kinoshita M (1993) Increased capillary permeability to albumin in diabetic rat myocardium. Circ Res 72:947-957

11. Stitt AW, Anderson HR, Gardiner TA, Archer DB (1994) Diabetic retinopathy: quantitative variation in capillary basement membrane thickening in arterial and venous environments. Br J Ophthalmol 78:133-137

12. Anderson HR, Stitt AW, Gardiner TA, Archer DB (1995) Diabetic retinopathy: morphometric analysis of basement membrane thickening of capillaries in different retinal layers within arterial and venous environments. $\mathrm{Br}$ J Ophthalmol 79:1120-1123

13. Boyd RB, Thompson VW, Atkin J (1996) Alterations in glomerular permeability in streptozotocin-induced diabetic rats. J Am Pediatr Med Assoc 86:57-62

14. Bendayan M, Gingras D, Charest P (1986) Distribution of endogenous albumin in the glomerular wall of streptozotocin-induced diabetics rats as revealed by high-resolution immunocytochemistry. Diabetologia 29:868-875

15. Ditzel J, Junker K (1972) Abnormal glomerular filtration rate, renal plasma flow and renal protein excretion in recent and short-term diabetes. BMJ 1:13-19

16. Farquhar MG, Hopper J, Moon HD (1959) Diabetic glomerulosclerosis; electron and light microscopic studies. Am J Pathol 35:721-753

17. Østerby R (1986) Structural changes in the diabetic kidney. Clin Endocrinol Metab 15:733-751

18. Bendayan M (1985) Alteration in the distribution of type IV collagen in glomerular basal lamina in diabetic rats as revealed by immunocytochemistry and morphometrical approach. Diabetologia 28: 373-378

19. Bradley JL, Thomas PK, King RHM, Watkins PJ (1994) A comparison of perineurial and vascular basal laminal changes in diabetic neuropathy. Acta Neuropathol (Berl) $88: 426-432$

20. Johnson PC (1983) Thickening of the human dorsal root ganglion perineurial cell basement membrane in diabetes mellitus. Muscle Nerve 6:561-565

21. Johnson PC, Brendel K, Meezan E (1981) Human diabetic perineurial cell basement membrane thickening. Lab Invest 44:265-270

22. Britland ST, Young RJ, Sharma AK, Clarke BF (1990) Relationship of endoneurial capillary abnormalities to type and severity of diabetic polyneuropathy. Diabetes 39:909-913

23. Yasuda H, Dyck PJ (1987) Abnormalities of endoneurial microvessels and sural nerve pathology in diabetic neuropathy. Neurology 37:20-28

24. Viberti GD, MacKintosh D, Keen H (1983) Determinants of the penetration of proteins through the glomerular barrier in insulin-dependent diabetes mellitus. Diabetes 32 [Suppl 2]:92-95

25. Hirose K, Østerby R, Nozawa M, Gundersen HJG (1982) Development of glomerular lesions in experimental longterm diabetes in the rat. Kidney Int 21:689-695

26. Brenner BM, Hostettet TH, Humes HD (1978) Glomerular permselectivity: Barrier function based on discrimination of molecular size and charge. Am J Physiol 234:F455F460

27. Desjardins M, Bendayan M (1990) Ultrastructural distribution of basement membrane components in experimental diabetes. Diabetes Res 14:65-73

28. Bendayan M (1998) Immunocytochemical detection of advanced glycated end products (AGE) in rat renal tissue as a function of age and diabetes. Kidney Int 54:438-447
29. Mooridian AD (1997) Central nervous system complications of diabetes mellitus; a perspective from the bloodbrain barrier. Brain Res Brain Res Rev 23:210-218

30. Lorenzi M (1980) The blood-brain barrier in diabetes mellitus. Adv Exp Med Biol 274:381-390

31. McCall A (1992) The impact of diabetes on central nervous system. Diabetes 41:557-570

32. McCall A, Millington WR, Wurtman RJ (1982) Metabolic fuel and amino acid transport into the brain in experimental diabetes mellitus. Proc Natl Acad Sci USA 79:54065454

33. Jakobsen J, Sideius P, Gundersen HJG, Østerby R (1987) Quantitative changes in cerebral neocortical structure in insulin-treated long-term streptozotocin-diabetic rats. Diabetes 36:597-601

34. Johnson PC, Brendel K, Meezan E (1982) Thickened cerebral cortical capillary basement membranes in diabetics. Arch Pathol Lab Med 106:214-217

35. Mukai N, Hori S, Pomeroy M (1980) Cerebral lesions in rats with streptozotocin-induced diabetes. Acta Neuropathol (Berl) 51:79-84

36. Junker U, Jaggi C, Bestetti G, Rossi GL (1985) Basement membrane of hypothalamus and cortex capillaries from normotensive and spontaneously hypertensive rats with streptozotocin-induced diabetes. Acta Neuropathol (Berl) 65:202-208

37. McCuskey PA, McCuskey RS (1984) In vivo and electron microscopic study of the development of cerebral diabetic microangiopathy. Microcirc Endothelium Lymphatics 1:221244

38. Bendayan M (1995) Colloïdal gold post-embedding immunocytochemistry. Prog Histochem Cytochem 29:1-159

39. Bendayan M, Rasio EA (1996) Transport of insulin and albumin by the microvascular endothelium of the rete mirabile. J Cell Sci 109:1857-1864

40. Ghitescu L, Bendayan M (1992) Hapten-tagged plasma proteins as immunocytochemical probes for the study of vascular permeability. Microsc Res Tech 22:392-401

41. Arshi K, Bendayan M, Ghitescu LD (2000) Alterations of the rat mesentery vasculature in experimental diabetes. Lab Invest 80:1171-1184

42. Ghitescu L, Bendayan M (1992) Transendothelial transport of serum albumin: a quantitative immunocytochemical study. J Cell Biol 117:745-755

43. Vorbordt AW, Dobrogowska DH (1994) Immunocytochemical evaluation of blood-brain barrier to endogenous albumin in adult, newborn and aged mice. Folia Histochem Cytobiol 32:63-70

44. Vorbordt AW, Dobrogowska DH, Tarnawski M, Meeker HC, Carp RI (1997) Immunocytochemical evaluation of bloodbrain barrier to endogenous albumin in scrapie-infected mice. Acta Neuropathol (Berl) 93:341-348

45. Madonick MJ, Margolis J (1952) Protein content of spinal fluid in diabetes mellitus. AMA Arch Neurol Psychiat 68:641-644

46. Kutt H, Hurwitz LJ, Ginsburg SM, McDowell F (1961) Cerebrospinal fluid protein in diabetes mellitus. Arch Neurol 4:43-48

47. Gregory RF, Mills GC, Gregory RL (1966) Cerebrospinal fluid lipids in diabetes mellitus. Diabetes 15:471-474

48. Naik RN, Wadia RS, Sartdesai HV, Mehta LN (1976) CSF in diabetic neuropathy-revisited. J Assoc Physicians India 24:845-850

49. Mompeo B, Popov D, Sima A, Constantinescu E, Simionescu M (1998) Diabetes-induced structural changes of venous and arterial endothelium and smooth muscle cells. J Submicrosc Cytol Pathol 30:475-484 
50. Poduslo JF, Curran GL (1994) Glycation increases the permeability of proteins across the blood-nerve and bloodbrain barrier. Brain Res Mol Brain Res 23:157-162

51. Stauber WT, Ong SH, McCuskey RS (1981) Selective extravascular escape of albumin into the cerebral cortex of the diabetic rat. Diabetes 30:500-503

52. Lorenzi M (1990) The blood-brain barrier in diabetes mellitus. In: Porter JC, Jezova D (eds) Circulating regulatory factors and neuroendocrine function. Plenum Press, New York, pp 381-390

53. Noguchi Y, Yamamoto T, Shibata Y (1986) Distribution of endothelial vesicles in the microvasculature of skeletal muscle and brain cortex of the rat, as demonstrated by tannic acid tracer analysis. Cell Tissue Res 246:487-494

54. Porter GA, Bankston PW (1987) Maturation of myocardial capillaries in the fetal and neonatal rat: an ultrastructural study with a morphometric analysis of the vesicle populations. Am J Anat 178:116-125

55. Lee MM, Schuessler GB, Lau K, Chien S (1988) Effects of pressure on vesicle size, density and distribution in the canine carotid arterial endothelium. J Ultrastruct Mol Struct Res 101:236-242

56. Bendayan M (2002) Morphological and cytochemical aspects of capillary permeability. Microsc Res Tech 57 (in press)

57. Bendayan M, Rasio EA (1997) Evidence of a tubular system for transendothelial transport in arterial capillaries of the rete mirabile. J Histochem Cytochem 45:1365-1378
58. Predescu D, Palade GE (1993) Plasmalemmal vesicles represent the large pore system of continuous microvascular endothelium. Am J Physiol 265:H725-H733

59. Feng D, Nagy JA, Hipp J, Dvorak HF (1996) Vesiculovacuolar organelles and the regulation of venule permeability to macromolecules by vascular permeability factor, histamine, and serotonin. J Exp Med 183:1981-1986

60. Londoño I, Bendayan M (1992) Endothelial cell protrusions in the rat aortic wall. Virchows Arch B Cell Pathol Incl Mol Pathol 61:419-422

61. Dvorak AM, Kohn S, Morgan ES, Fox P, Nagy JA, Dvorak HF (1996) The vesicule-vacuolar organelle (VVO): a distinct endothelial cell structure that provides a transcellular pathway for macromolecular extravasation. J Leukoc Biol 59:100-115

62. Lossinsky AS, Vorbrodt AW, Wisnieski HM (1983) Ultracytochemical studies of vesicular and canalicular transport structures in the injured mammalian blood-brain barrier. Acta Neuropathol (Berl) 61:239-245

63. Ueno M, Dobrogowska DH, Vorbrodt AW (1996) Immunocytochemical evaluation of the blood-brain barrier to endogenous albumin in the olfactory bulb and pons of senescence-accelerated mice (SAM). Histochem Cell Biol 105:203-212

64. Londoño I, Ghitescu L, Bendayan M (1995) Glomerular handling of glycated albumin in the normal mouse kidney. Am J Physiol 268:F913-F921 